\title{
A ONG AÇÃO MORADIA: \\ INFLUENNCIA DO TERCEIRO SETOR NA PERIFERIA
}

Milena Abadia de Sousa ${ }^{1}$

Gabriel Humberto Muñhoz Palafox ${ }^{2}$

\section{RESUMO}

O presente artigo tem como objetivo descrever e analisar a história, estrutura e funcionamento da ONG "Ação Moradia" localizada na periferia da cidade de Uberlândia/MG, bem como os limites e possibilidades da sua contribuição no âmbito do Terceiro Setor brasileiro. A pesquisa é resultado de uma Dissertação de Mestrado realizada no Programa de Pós-Graduação em Educação, na linha de pesquisa "Estado, Política e Gestão da Educação".

Palavras-chave: Espaço Urbano; Periferia; Terceiro Setor; ONG; Formação Humana.

\section{ABSTRACT}

This article aims to describe and analyze the history, structure and functioning of the NGO "Action House" located on the outskirts of the city of Uberlândia / MG, as well as the limits and possibilities of their contribution in the Brazilian Third Sector. The research is the result of a Master's Thesis performed in the Post-Graduate Education in the search line "State Policy and Management Education".

Keywords: Urban Space; Periphery; Third sector; NGOs; Human Formation. 


\section{Introdução}

O presente trabalho é resultado de uma Dissertação de Mestrado realizada no Programa de Pós-graduação em Educação da Universidade Federal de Uberlândia, MG, na linha de pesquisa Estado, Política e Gestão da Educação.

O objetivo da pesquisa foi descrever e analisar a história, estrutura e funcionamento da Organização Não-Governamental - ONG “Ação Moradia” localizada na periferia da cidade de Uberlândia/MG, bem como os limites e possibilidades da sua contribuição no âmbito do Terceiro Setor brasileiro. A investigação se configura no campo da pesquisa qualitativa em educação.

Durante a minha adolescência me tornei moradora do bairro Morumbi da cidade de Uberlândia, Minas Gerais, local onde se encontra a ONG "Ação Moradia", e, posteriormente no período 2009-2013, na condição de estudante do curso de Geografia da UFU, tive oportunidade de participar da realização de um Projeto de Extensão que contou justamente com a parceria dessa mesma ONG.

Nesse contexto, tanto de vida cotidiana quanto de extensão e pesquisa, tive oportunidade de presenciar e conhecer parte dos conflitos, interesses econômicos, problemas estruturais e ocupações irregulares que caracterizaram a organização do espaço urbano dos bairros localizados no entorno dessa ONG, bem como identificar um conjunto de necessidades e demandas sociais, de natureza urbana, econômica e, inclusive, de formação profissional, surgindo o interesse científico, em investigar à luz da realidade concreta, quais seriam os limites, possibilidades e perspectivas históricas da ONG Ação Moradia na periferia de Uberlândia.

Baseada nos fundamentos da pesquisa qualitativa e a utilização de técnicas de coleta de dados bibliográficos, documentais e daqueles resultantes de trabalho de campo, a interpretação de tais dados, foi fundamentada em um processo dialético-hermenêutico de descrição, determinação e precisão conceitual rigorosa da realidade (MARTINS, 1994).

Nesse sentido, a pesquisa bibliográfica abrangeu o estudo de livros, teses e artigos impressos e virtuais que abordam as políticas públicas voltadas, em especial, para o Terceiro Setor e as relações urbanas. Quanto à pesquisa documental, foram analisadas leis, documentos oficiais que se relacionam com o Terceiro Setor e as ONGs no Brasil.

O processo de coleta de dados foi efetivado por meio da utilização da técnica de entrevista semiestruturada. Dessa forma e considerando também as limitações de realização temporal da pesquisa, os sujeitos entrevistados foram cinco gestores fundadores da instituição; cinco trabalhadores que também são participantes dos programas e projetos sociais ofertados pela instituição ao longo da sua existência, cinco usuários e cinco exusuários da citada ONG.

Para a identificação dos usuários e ex-usuários a serem entrevistados, foi elaborada uma listagem a partir de um levantamento de nomes e demais dados pessoais encontrados em documentos dentre aqueles que participaram no ano de 2015 (usuários) e no período de 2010-2013 (ex-usuários). Em seguida foi utilizada a técnica de amostragem sistemática para identificar os entrevistados por meio da utilização de uma planilha eletrônica.

No momento de procurar às pessoas selecionadas (sorteadas) para serem entrevistadas, foram encontradas dificuldades ao perceber que a maior parte dos dados fornecidos pela ONG estavam defasados, situação esta que implicou na estratégia de complementar a listagem de sujeitos da pesquisa recorrendo à identificação de ex-usuários por meio da consulta a outros ex-usuários que foram efetivamente localizados e que concordaram em participar da pesquisa. 
No que diz respeito aos procedimentos de organização e análise dos dados resultantes do trabalho de campo foi utilizado o método de interpretação hermenêuticodialético da realidade, considerando que:

conhecer o mundo significa compreender e interpretar os processos que determinam a forma de existência dos objetos ou fenômenos num determinado contexto histórico, sabendo que em outro eles são diferentes, não se ocupando, portanto, das discussões metafísicas sobre a essência do mundo em si mesmo (MUÑOZ PALAFOX, 2013, p. 18).

Muñoz Palafox (2013) ainda ressalta que a pesquisa nas ciências humanas implica em um exercício guiado e medido pela teoria, esta vista como uma aquisição histórica produzida na interação dialética entre os homens e o mundo.

Para realização da pesquisa, a identidade de todos os sujeitos entrevistados foi preservada, por meio da identificação de um código, tal como apresentado na tabela abaixo.

Tabela 01. Organização dos sujeitos da pesquisa por meio de categorias de participação.

\begin{tabular}{c|c|c|c}
\hline Grupos & $\begin{array}{c}\text { Identificador do } \\
\text { Entrevistado }\end{array}$ & $\begin{array}{c}\text { Categorias de } \\
\text { participação }\end{array}$ & $\begin{array}{c}\text { Entrevistados (Total= } \\
\mathbf{2 0} \text { ) }\end{array}$ \\
\hline $\mathbf{A}$ & A1, A2, A3, A4, A5. & $\begin{array}{c}\text { Grupo de usuários da } \\
\text { ONG. (Usuários). }\end{array}$ & $\mathbf{5}$ \\
\hline $\mathbf{B}$ & B1, B2, B3, B4, B5 & $\begin{array}{c}\text { Grupo de Ex-usuários da } \\
\text { ONG. }\end{array}$ & $\mathbf{5}$ \\
\hline $\mathbf{C}$ & C1, C2, C3, C4, C5. & $\begin{array}{c}\text { Grupo de Funcionários } \\
\text { da ONG, ex-usuários. }\end{array}$ & $\mathbf{5}$ \\
\hline $\mathbf{D}$ & D1, D2, D3, D4, D5 & Gestores da ONG. & $\mathbf{5}$ \\
\hline
\end{tabular}

Fonte: Organizado pela autora.

\section{A cidade de Uberlândia, o bairro Morumbi e seu entorno.}

A cidade de Uberlândia/MG conta com uma população aproximada de 600.000 habitantes, sendo considerada uma das principais cidades do interior de Minas Gerais, isso devido tanto por sua localização, como também o clima, os bons solos, e as relações econômicas constituídas no decorrer de sua história. Com suas bases históricas constituídas com discurso de "ordem" e "progresso", o ideal de "cidade acolhedora", sem problemas urbanos, atraiu um número muito grande de migrantes à procura de melhores condições de vida.

O próprio nome da cidade, escolhido no ano de 1929, afirma esse discurso. Uberlândia que significa terra fértil, uber (fértil), land (terra), sendo que uber também é de origem germânica e significa superior, sendo então sua junção "terra superior". Ou seja, a cidade que supera todas as outras em progresso e ordem.

A questão é que a cidade não tinha aporte suficiente para receber esses migrantes da maneira que deveria, e assim que eles chegavam a Uberlândia se deparavam com a falta de emprego, alto custo de vida, restando muitas vezes como única alternativa de moradia, os 
conjuntos habitacionais ou até mesmo a ocupação "irregular" de terrenos públicos e privados.

Em 1989, época em que Fernando Collor de Melo foi eleito presidente sob o discurso eleitoral de trazer esperança e motivação para a população brasileira, inclusive no campo das políticas habitacionais, dentro do qual o próprio candidato à presidência teria anunciado a existência de um déficit de 10 milhões de moradias no país (ARAÚJO SOBRINHO, 1995), foi criado o Programa de Ação Imediata em Habitação - PAIH em parceria com as prefeituras municipais.

O PAIH em Uberlândia foi implantado para viabilizar, dentre outros, o Loteamento Santa Mônica II que no futuro foi batizado com o nome de "Bairro Morumbi", alvo da pesquisa, onde se encontra a ONG Ação Moradia. Neste loteamento foram construídas 2.250 casas em regime de "embrião" constituído de uma área de 10 metros de largura por 25 de comprimento, com um banheiro e sem paredes internas.

Num dos poucos trabalhos localizados na pesquisa bibliográfica realizada, Araújo Sobrinho (1995), afirma que, na prática, a distribuição das casas construídas com recursos do PAIH foi efetivada por meio de um processo de indicação política daqueles que receberiam as casas, gerenciado pelo poder local da época. Dentre outros aspectos, o conjunto Habitacional Santa Mônica II foi construído propositalmente a pelo menos $11 \mathrm{~km}$ do centro da cidade com a finalidade de propiciar a criação de espaços urbanos intermediários cujos terrenos seriam com o passar do tempo, seguramente valorizados de acordo com as práticas de especulação imobiliária estabelecidas pelo mercado local e de acordo com o nível de desenvolvimento econômico-comercial. Na prática, esse programa foi uma forma de reafirmar os ideais progressistas da cidade, bem como, uma estratégia de parceria entre os agentes imobiliários e o Estado. 
Figura 1. Uberlândia (MG): Localização bairros Morumbi e Residencial Integração em relação ao centro da cidade.
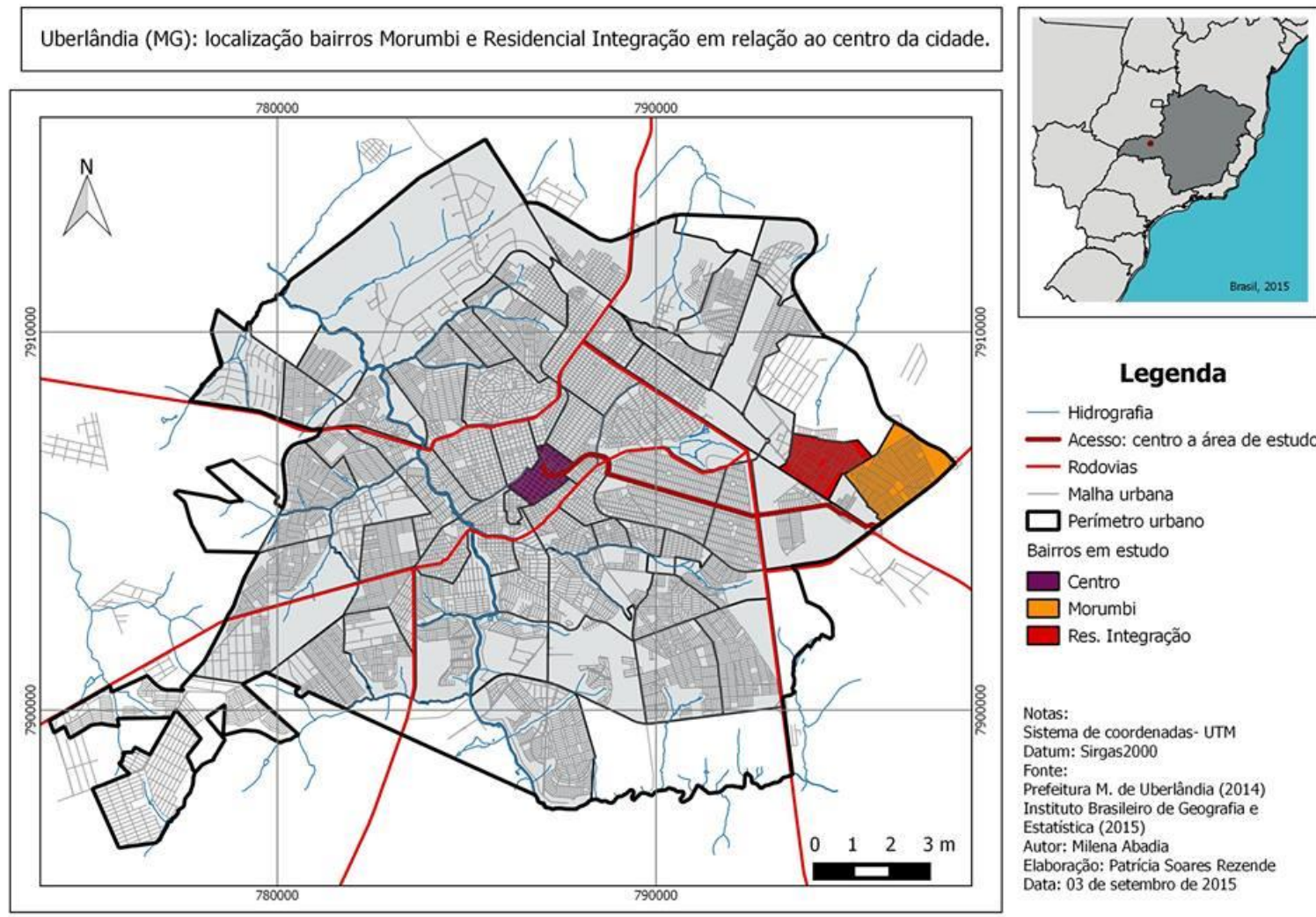

Legenda

- Hidrografia

- Acesso: centro a área de estudo

- Rodovias

- Malha urbana

$\square$ Perímetro urbano

Bairros em estudo

$\square$ Centro

$\square$ Morumbi

Res. Integração

Notas:

Sistema de coordenadas- UTM

Datum: Sirgas 2000

Fonte:

Prefeitura M. de Uberlândia (2014)

Instituto Brasileiro de Geografia e

Estatistica (2015)

Elaboração: Patricia Soares Rezende

Data: 03 de setembro de 2015

Fonte: REZENDE, P.S. (Org.). Prefeitura Municipal de Uberlândia, Uberlândia: Secretaria de Planejamento Urbano, 2015.

Diante das características e dinâmicas de implantação do PAIH no loteamento Santa Mônica II, pode ser observado que o citado programa além de atender parcialmente ao déficit de moradia existente no município, foi constituído por um tipo de construção altamente precarizada que, no nosso entendimento, dificilmente seria capaz de atender as demandas da população em termos de moradia. Uma vez que foi possível constatar que a sua construção caracterizava-se não somente por falta de um adequado acabamento (reboco, piso, muro e alicerce), mas também pelo fato de que o material empregado na construção, devido a baixa qualidade do mesmo, começou a se deteriorar rapidamente "gerando um desperdício elevado durante a construção e constantes trocas e reposições, após as ocupações da moradia" (ARAÚJO SOBRINHO, 1995, p. 59).

Além disso, vale ressaltar também que, de acordo com Araújo Sobrinho (1995), o local escolhido para implantar o PAIH apresentou situações de risco e problemas ambientais, tal como ocorreu, de fato, com o bairro Morumbi cujas casas foram construídas em uma área de chapada, bastante rochosa cuja declividade plana provoca, dentre outras dificuldades, a pouca impermeabilização da água das chuvas por falta de escoamento adequado. Problema este que os moradores enfrentam até hoje, principalmente, em época de chuvas quando é comum ocorrerem inundações nas ruas que ocasionam, inclusive, a invasão da água para dentro das residências.

O problema das enchentes já se tornou tão rotineiro no bairro, que todos os anos são narradas nos jornais as consequências decorrentes deste tipo de fenômeno, o qual entendemos, deixou de ser somente natural, para se transformar em um problema de natureza social e política. 
O tipo de solo da região, o Latossolo vermelho ou roxo também contribui para a erosão e no período da seca provoca grande quantidade de poeira, o que acaba causando um desconforto para a população. Quando não é o período de poeira, o contratempo se encontra no período de enchentes, causando vários problemas, inclusive de saúde. Além de ser construído em locais inadequados, o poder municipal local não cumpriu com o acordo de levar a infraestrutura básica para esses bairros, fazendo com que a população sofresse até os dias de hoje com a falta de pavimentação de ruas, ausência de equipamentos urbanos, como escolas, postos de saúde, transporte coletivo, entre outros.

Em resumo,

[...] não houve na época do planejamento e construção qualquer preocupação no sentido de se produzir um espaço agradável e bem planejado, que possibilitasse uma melhor utilização por parte de seus moradores. Pelo contrário, apenas interessava o número de casas construídas e a urgência de concluí-las (ARAÚJO SOBRINHO, 1995, p. 73).

Além do conjunto habitacional, o entorno do bairro Morumbi passou por um processo de ocupações irregulares por volta do ano de 2004, esse processo aconteceu principalmente por fatores econômicos, ligados também ao movimento migratório.

Segundo dados do IBGE (2010), o bairro Morumbi conta com uma população de aproximadamente 18.000 habitantes, possui um número de 5.677 domicílios, o maior número de população está entre 15 e 19 anos. A renda mensal de $47 \%$ da população está entre dois a cinco salários mínimos.

Segundo pesquisas da Secretaria de Desenvolvimento Social de Uberlândia, o bairro Morumbi está entre os dez bairros uberlandenses que contém a maior quantidade de famílias com renda per capita de até $\mathrm{R} \$ 77$ (setenta e sete reais), grupos estes que vivem em condições de extrema pobreza.

Ao entorno do bairro Morumbi, encontra-se o Residencial Integração, que teve início através de um processo de ocupação. Tem uma população aproximada de 14.000 habitantes que vivem em 4.953 domicílios, segundo IBGE (2010). O maior número de sua população está entre 10 a 14 anos somando um total de 1.544 crianças e adolescentes. Ressaltando que os dados referentes ao Residencial Integração não são completos, devido á rápida dinâmica das ocupações "irregulares".

As constatações teóricas dos problemas e dos dilemas do bairro Morumbi, somente confirmam aquilo que enquanto moradora do bairro há mais de 15 anos é possível perceber cotidianamente, porém com a diferença de que agora é possível identificar que tais problemas e dilemas não ocorreram de forma natural, mas que são e constituíram parte de um processo de organização do espaço urbano pautado numa lógica de mercado que, sem qualquer pretensão de análise "conspirativa", representou sim, apenas mais uma daquelas estratégias do capitalismo direcionadas para a obtenção de lucro, em detrimento objetivo das demandas efetivas da população de baixa condição socioeconômica.

Com a pesquisa de campo realizada, foi possível constatar tanto os problemas da constituição quanto as dificuldades atuais do Morumbi e do Residencial Integração.

De todos os entrevistados, 14 são moradores dos bairros ao entorno da ONG há mais de 15 anos, e 7 deles vivenciaram o processo de ocupação. Foi possível constatar que as dificuldades iniciais eram voltadas para questões estruturais do bairro como falta de água, esgoto, asfalto, estes, principalmente encontrados nas ocupações.

Normalmente essas ocupações acontecem em locais sem nenhuma condição de moradia, locais estes que não são preparados para receber casas, famílias. Com a falta de 
energia elétrica, rede de água e esgoto, essas pessoas precisam improvisar para adquirir esses serviços. A iluminação das ruas e das casas e a ligação da água são feitas pelos próprios moradores, essas conjunturas são chamadas popularmente de "gatos". O esgoto é descartado por fossa séptica ou em algumas vezes ficam a céu aberto.

Nossa! Quando nóis invadiu pra cá não tinha água, não tinha luz, não tinha asfalto, não tinha nada. Nóis morou num barraco, ainda ficou muito tempo pegando água no caminhão pipa, eles cedendo água para nóis (C3).

Na época quando eu fui pra lá a situação do bairro era precária. Por quê? Porque num tinha rede de esgoto ainda né? [...] era algumas ruas só que tinha iluminação, era muito escuro. [...] mas era algumas lâmpadas, porque na época não tinha postes de energia, e em alguns lugares era sem energia, era escuro (C5)

Davis (2006) aponta que muitas vezes o custo de se morar em um local sem serviços públicos e longe do centro urbano faz com que a ocupação não seja tão barata assim em relação à compra de um terreno, mas a atratividade está em conseguir construir aos poucos e ir melhorando a moradia, bem como não ser necessário desembolsar um valor alto para a compra do terreno. Normalmente quando essas ocupações são regularizadas, os moradores pagam valores mensais para a prefeitura, custos estes calculados segundo a renda familiar, quanto mais alta a renda, mais alto será o valor da prestação.

Depois de relatarem as dificuldades do início dos bairros, foi lhes questionado quais dificuldades ainda são encontradas e se são as mesmas do início. Foi interessante perceber que as dificuldades estruturais deixaram de ser as principais. Após a chegada da estrutura física, as problemáticas voltaram-se, principalmente, para equipamentos urbanos, como falta de escola, saúde, não que essas questões não estivessem presentes no começo do bairro, mas as questões básicas como água, energia, naquele momento eram prioritárias.

Dentre os problemas atuais elencados, está o transporte. A maioria da população de bairros periféricos depende do transporte público, condução essa que gera muitos transtornos, seja pelo ônibus estar sempre cheio, ou pela demora. Nesse sentido, Santos contribui afirmando que,

As camadas inferiores da sociedade urbana estão subordinadas a meios de locomoção frequentemente precários e pelos quais devem pagar uma parcela cada vez maior dos seus ganhos. Essa vocação é agravada por dois fatores concomitantes: a expansão territorial da cidade e a diversificação do consumo das famílias (SANTOS, 1990, p. 79).

A falta de condições para atender a saúde também foi apontada nas falas.

Eu acho que precisa melhorar a saúde com certeza, esses dias eu fui ao UAI e foi terrivel sabe? A gente tem que orar muito pra não ficar doente, é muito ruim. Tipo pouco médico pra muita gente [...] Lá são dois clínicos gerais e muita gente pra ser atendida, então você vai pra lá e fica horas e horas, não é legal, porque por exemplo, se você tiver precisando de atendimento, se você não tiver se sentindo nada bem vai ficar pior (B1).

É possível notar como essa população fica à margem da cidade e que, geralmente, os serviços básicos, neste caso a saúde, são deixados de lado ou chegam até esses bairros 
em condições precárias e insuficientes. Os investimentos, muitas vezes, ficam aglomerados no centro e nos bairros mais "valorizados" economicamente, o que é algo contraditório, pois a população que não tem condições de pagar por tais serviços acaba tirando do pouco que ganha para suprir essas necessidades ou morrem nas filas de espera dos hospitais em busca de atendimento.

Os bairros cuja população dispõe de uma renda alta são mais bem contemplados com serviços públicos do que aqueles onde a renda é mais baixa [...] A explicação deve ser encontrada na decisão política de satisfazer a certas camadas de população, em detrimento de outras, mesmo quando estão em jogo serviços essenciais (SANTOS, 1990, p. $55)$.

Além dos transportes e da saúde, a educação foi mencionada em vários depoimentos. O número de escolas e creches é insuficiente para atender a demanda dos bairros, sendo necessário o deslocamento para escolas distantes.

[...] escola também não tem escola perto. Meu filho estuda no Alvorada, tem que pegar o ônibus. Ele está fazendo a $6^{\circ}$ série, tem 10 anos e tem que ir lá pro Alvorada. Ele pega o ônibus e vai (C5).

A falta de opções de lazer também foi mencionada,

Então, lazer aqui eu acho que não tem, porque na verdade eu não saio muito. Eu fico mais da escola pra casa. Mas aqui tem aquela praça do Dom Almir que não tem nada [...]Sim eu saio do bairro. Eu vou pra outro lugar com meus amigos, aqui no bairro não tem o que fazer (B1).

A longa jornada de trabalho desses moradores, somados ao alto custo das opções de lazer na cidade e as dificuldades já mencionadas em relação ao transporte público, fazem com que essas pessoas deixem de lado a perspectiva de terem qualidade de vida. Não ter opções de lazer principalmente para as crianças e jovens, segundo os entrevistados está relacionado diretamente com a violência e as drogas, problemas vivenciados no cotidiano dos bairros.

A violência estampada nos jornais e na televisão faz com que esses bairros sejam reconhecidos no imaginário social por meio desse fator, criando-se, dessa forma, uma identidade cultural para o território e para os seus moradores, os quais além de conviver de alguma forma com o medo resultante da violência, preferem evitar fazer comentários sobre tais assuntos.

Ainda de acordo com Ramires e Santos (2009), o bairro Morumbi, vinha, de fato, "se consolidando como um importante território da violência em Uberlândia, e, por conseguinte, estigmatizado no conjunto da cidade, tanto por seus moradores, como os residentes de outros bairros" (RAMIRES; SANTOS, 2009, p. 143).

Portanto, refletir sobre o espaço urbano é refletir sobre o modo de vida das pessoas, é avaliar sobre seus valores, ideais, cultura, entre outros, afinal o espaço é fruto da produção humana, "logo pensar o urbano significa pensar a dimensão do humano" (CARLOS, 2005 p. 70). E o espaço sendo produto histórico do humano, faz com que,

O urbano produzido através das aspirações e necessidades de uma sociedade de classes fez dele um campo de luta onde os interesses e as 
batalhas se resolvem pelo jogo político das forças sociais. O urbano aparece como obra histórica que se produz continuamente a partir das contradições inerentes á sociedade (CARLOS, 2005, p. 71).

A busca pelos direitos básicos como alimentação, moradia, saúde, educação dentre outros, faz com que pessoas da sociedade civil se organizem de várias formas para conquistar tais direitos. As ONGs fazem parte deste cenário e estão dentro do chamado Terceiro Setor, esfera esta que não visa fins lucrativos. A finalidade principal das ONGs é atender as demandas da sociedade as quais o Estado não conseguiu suprir.

\section{Terceiro Setor e a ONG Ação Moradia}

O termo Organização Não-Governamental (ONG) surgiu em 1945 em um documento da ONU. Essa expressão foi criada para dar nome às entidades que recebiam dinheiro de órgãos públicos para desenvolver projetos de interesses sociais.

Segundo Camba,

As ONGs podem ser definidas atualmente como grupos que buscam, por um lado, influenciar e democratizar políticas governamentais, para que estas supram da maneira mais extensa possível as necessidades da sociedade e de condições de vida iguais e justas no mundo todo, e por outro lado, movimentar a sociedade em que estão inseridas, utilizando-se de suas relações de solidariedade, na busca dessa democratização e influência política (CAMBA, 2009, p. 24).

Num interessante artigo publicado por Joana Coutinho (2004) é apresentada uma revisão de literatura sobre o Terceiro Setor, com foco nas organizações nãogovernamentais. A autora afirma que o termo ONG começou a ser utilizado na década de 1940, pela ONU, para denominar diferentes entidades proponentes e executoras de projetos humanitários ou de interesse público, enquanto no Brasil, esta nomenclatura foi utilizada inicialmente para as organizações de cooperação internacional formadas por igrejas (católica e protestante), organizações de solidariedade e governos de vários países.

Perante o Código Civil Brasileiro, o termo ONG:

[...] não existe legalmente e conforma-se como um conceito que vem sendo socialmente construído e difundido, no Brasil, desde os anos 1970, voltado para definir entidades, que no cenário internacional quanto nacionalmente, vêm ganhando projeção social e política (PEREIRA, 2003, p. 36).

As ONGs perante a lei são uma associação ou uma fundação. Associação significa a união de pessoas que se organizam para fins não econômicos. Esse fim pode ser dos mais diversos, como científica, cultural, esportiva, literária, entre outros.

Segundo o manual do Terceiro Setor do Instituto Pró Bono (2005), a finalidade de uma associação pode ser "altruística - como uma associação beneficente que atende a uma comunidade sem restrições qualificadas - ou não altruística, no sentido de que se restringe a um grupo seleto e homogêneo de associados" (PRÓ BONO, 2005, p. 10).

Já para ser uma fundação, é necessário contar com um capital inicial, que muitas vezes é deixado por meio de escritura pública ou testamento, onde os bens são destinados á fins religiosos, culturais, morais ou de assistência. "Assim, as fundações formam-se pela 
constituição de um patrimônio dotado de personalidade jurídica destinado a cumprir uma finalidade social segundo a vontade de seus instituidores" (PRÓ BONO, 2005, p. 11).

Ou seja,

ONG, entidade ou instituição da sociedade civil, será sempre - em termos jurídicos - uma associação ou uma fundação. A escolha fica a critério daqueles que a estabelecem, mas, inexistindo bens para a dotação de um patrimônio inicial, a criação de uma fundação torna-se impossível. É por esta razão que pequenas e médias ONGs, grupos de apoio e pesquisa, grupos comunitários etc., em geral são constituídos como associações. Entidades financiadoras, grandes instituições educacionais, grupos fomentadores de projetos e pesquisas, contrariamente, são em geral organizadas como fundações (PRÓ BONO, 2005, p. 15).

Dentro desse contexto, a ONG Ação Moradia foi informalmente organizada em 1993 para coordenar coletivamente ações assistenciais de natureza filantrópica que foram orientadas para o atendimento de grupos familiares localizados em ocupações "irregulares" urbanas, bem como famílias de baixa renda da periferia de Uberlândia.

Os seus organizadores foram pessoas moradoras de Uberlândia, ligadas à igreja católica, e à medida que tais ações foram ampliadas, no ano 2004 ela foi formal e juridicamente transformada em uma associação comunitária ligada ao Terceiro Setor como Organização Não-Governamental.

Com apoio da igreja católica, o grupo começou a arrecadar dinheiro para promover ações destinadas à contribuir com a resolução de parte dos problemas sociais encontrados nesses bairros. O trabalho, tanto dos cursos e atividades pedagógicas realizados com as crianças da comunidade, quanto do acompanhamento das famílias atendidas sempre foi voluntário, e o recrutamento de tais voluntários acontecia por meio da divulgação informal das atividades da pastoral, principalmente nas igrejas católicas.

As ações da entidade eram organizadas a partir das demandas identificadas. Segundo o gestor D1,

Quando a gente foi lá pra esse bairro, a gente começou a dar aula de artesanato dentro da igreja e aí precisava de ter alguém para olhar as crianças, porque as mãe levavam as crianças, aí precisava de dar alimento para essas crianças e aí começou a preocupar com as crianças, então foi assim sabe? (D1).

Com o passar dos anos, diante das mudanças conjunturais ocorridas no entorno dos bairros atendidos pela Pastoral da Moradia, da posterior desvinculação de sua relação com a igreja católica, da construção da sua nova sede contando com parceiros públicos e privados, assim como, da reorientação política dos seus membros fundadores e voluntários para a busca interinstitucional de recursos financeiros para além daqueles arrecadados pela lógica das doações, a associação viu redefinidas as suas atividades dentro de um campo agora juridicamente estabelecido.

De acordo com o gestor entrevistado, a ONG atende anualmente uma média de 400 famílias, que totalizam aproximadamente 1.200 pessoas. A comunidade atendida se divide entre crianças, adolescentes e adultos, com uma significativa predominância de mulheres, que, de acordo com os gestores da ONG, se deve principalmente à questão socioeconômica e cultural da população atingida pela ONG. 
Nós temos uma comunidade que passa por dificuldades inerentes até ao processo de formação, como se formou o bairro, um processo de assentamento, e que tem sua raiz nas dificuldades financeiras, agrupa também pessoas que tiveram poucas oportunidades de formação educacional na vida. Isso faz com que o perfil de nosso público acabe sendo no geral, famílias que vivem em situação de vulnerabilidade social, ou muitos até já em riscosocial. Isso faz com que também nesse grupo de vulnerabilidade, as mais vulneráveis sejam as mulheres. E por outro lado, mesmo sendo as mais vulneráveis, são as pessoas que mais tem vínculo com a família e com os filhos e que desejam melhorias de vida (D3).

A ONG Ação Moradia tem como finalidade "prestar serviços gratuitos, de forma permanente, sem qualquer discriminação e congregar iniciativas comunitárias, objetivando a promoção humana junto às comunidades de baixa renda" (AÇÃO MORADIA, 2004, p. 1). Desse modo, a ONG delimitou alguns campos de atuação, são eles: Moradia; Atividades profissionalizantes para o autossustento; Segurança alimentar; Formação moral, cultural e cidadã; Colaboração com outras entidades com objetivos semelhantes.

Para alcançar seus objetivos a ONG traçou frentes de trabalho. Em relação á moradia, as primeiras atividades aconteciam pontualmente por meio da doação de materiais de construção para as famílias que viviam em barracos de lona. Essas doações eram desde portas, telhas, tijolos, até utensílios para a casa, como filtros de água. Só após a abertura de uma fábrica de tijolos ecológicos na sede da Ação Moradia, que a ONG conseguiu atuar de forma efetiva na construção de casas para algumas famílias.

Em 2005, em parceria com a Caixa Econômica Federal (CEF) e a prefeitura de Uberlândia, a ONG desenvolveu um projeto destinado à construção de 50 casas populares, sendo que o banco liberou os recursos financeiros e a prefeitura cedeu os terrenos, no bairro Campo Alegre, localizado na região Sul do município.

As famílias de baixa renda socioeconômica beneficiadas pelo o projeto foram selecionadas por sorteio, sendo a ONG responsável pelo processo seletivo cujos principais critérios de inscrição foram comprovar que eram moradoras do município e não possuir casa própria.

Além da parceria com a caixa econômica, a ONG fez outras ações pontuais em relação à moradia, seja na melhoria de algumas casas, ou na construção de outras onde somente havia barracos. 
Figura 2. Troca do "barraco" por casa de tijolos ecológicos.

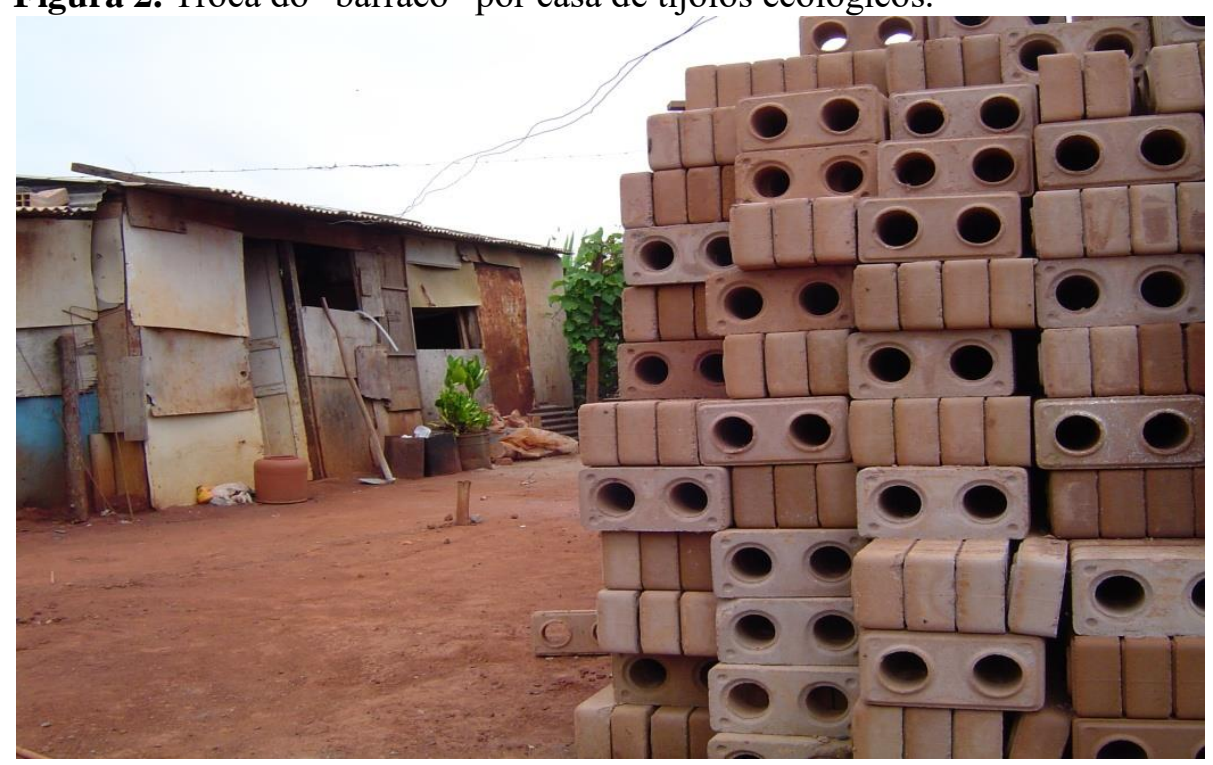

Fonte: Imagem cedida pela ONG Ação Mordia (Sem data).

Para Meira, a conquista da casa própria, é como uma "possibilidade emancipatória, de um direito alcançado, enfim, de vencer na vida, uma vez que como proprietários, são agora pertencentes de fato à comunidade" (MEIRA, 2009, p. 141). Concordando com o autor, os membros da comunidade afetada pela ONG, aqui entrevistados, apontaram claramente um marco divisor entre "o antes e o depois" da casa própria. Uma vida sofrida antes e uma nova vida depois de concluídas as suas moradias.

Em relação a formação voltada para o autossustento, a ONG desenvolveu desde o início de suas atividades cursos profissionalizantes partindo do pressuposto básico de que seria necessário contribuir com a capacitação da comunidade com a finalidade de poder inserí-la no mercado de trabalho como forma de autossobrevivência.

Os cursos são voltados para a área de estética, artesanato, informática, assim como, aprendizagem em inglês e cursos para gestantes do primeiro filho. De acordo com os gestores da ONG, as áreas temáticas dos cursos foram sendo definidas, principalmente, conforme a disponibilidade de voluntários dispostos a ministrar oficinas.

Além dos cursos, a ONG desenvolveu um projeto de incubação de empreendimentos solidários, visando à melhoria das condições socioeconômicas das famílias atendidas pela ONG. Segundo uma das gestoras, a vontade de ingressar no campo da Economia Solidária, surgiu quando perceberam em 2008 que os usuários da ONG basicamente realizavam cursos de capacitação para obtenção de certificados, mas sem a certeza de que as famílias pudessem com isso conquistar ou alcançar os meios para seu próprio autossustento.

Quando os usuários terminavam os cursos, eles eram convidados a participar da Unidade Produtiva - nome dado pela ONG para os empreendimentos -, para adquirirem noções sobre empreendedorismo e Economia Solidária, como forma de obter subsídios para que no futuro pudessem gerir seu próprio negócio.

Segundo França Filho (2002), as primeiras experiências de Economia Solidária foram associadas ao movimento operário associativista organizado no século XIX na Europa. Característico da dinâmica de resistência popular, este movimento promoveu experiências solidárias de geração de trabalho e renda, influenciadas pela ideia da ajuda mútua, a cooperação e a associação coletiva, o seja, a Economia Solidária é compreendida 
[...] como iniciativas oriundas dos setores populares, combinando, ao mesmo tempo, na sua ação organizacional, uma dimensão social e uma dimensão econômica sob um fundo de luta política, essas experiências modificam aos poucos o conteúdo de sua prática, ou seja, mudam de fisionomia ao longo da história (FRANÇA FILHO, 2002, p.12).

Nesse sentido, pensar a Economia Solidária significa pensar uma sociedade que não esteja centrada nos ideais de mercado. Ela é centrada em um "conjunto amplo de iniciativas econômicas que estão marcadas pelo esforço coletivo da colaboração, da união, da organização e da síntese cultural" (CRUZ; GUERRA, 2009, p.5).

Entretanto e apesar da proposta, pode ser observado que a realidade concreta imposta pelo mundo do trabalho formal terminou sobre determinando toda a política da ONG neste setor, à medida que a baixa remuneração, a impossibilidade objetiva dos exusuários montarem seus próprios negócios, assim como também, a impossibilidade de nem sequer conseguir emprego formal fora da ONG.

Em relação à política de segurança alimentar, além da doação de cestas básicas para famílias de baixa condição socioeconômica a ONG organiza um almoço de natal que acontece anualmente na sede da instituição. Para o almoço são convidadas as famílias que fizeram alguma atividade na ONG durante o ano. Em 2015 a programação do almoço de natal contemplou apresentações culturais das crianças atendidas pela ONG, concurso de poesia, dentre outros. Foram esperadas cerca de 1.900 pessoas. Tanto o almoço quanto a distribuição de cestas básicas acontecem por meio de doações.

Em relação a formação cultural e cidadã, a ONG começou a organizar atividades artísticas, culturais esportivas e de cidadania associadas à complementação alimentar para crianças e adolescentes, em horários matutino e vespertino, complementares ao da escola de ensino regular.

A ideia central de tais atividades é contribuir em termos educacionais para proporcionar orientações úteis para a vida e o exercício da cidadania por meio de ações culturais, de lazer, esportivas e artísticas, entendidas estas como parte de uma vivência "diferenciada" entre as crianças da periferia, capaz de promover uma formação voltada futuro.

Figura 3. Apresentação Cultural na ONG Ação Moradia.

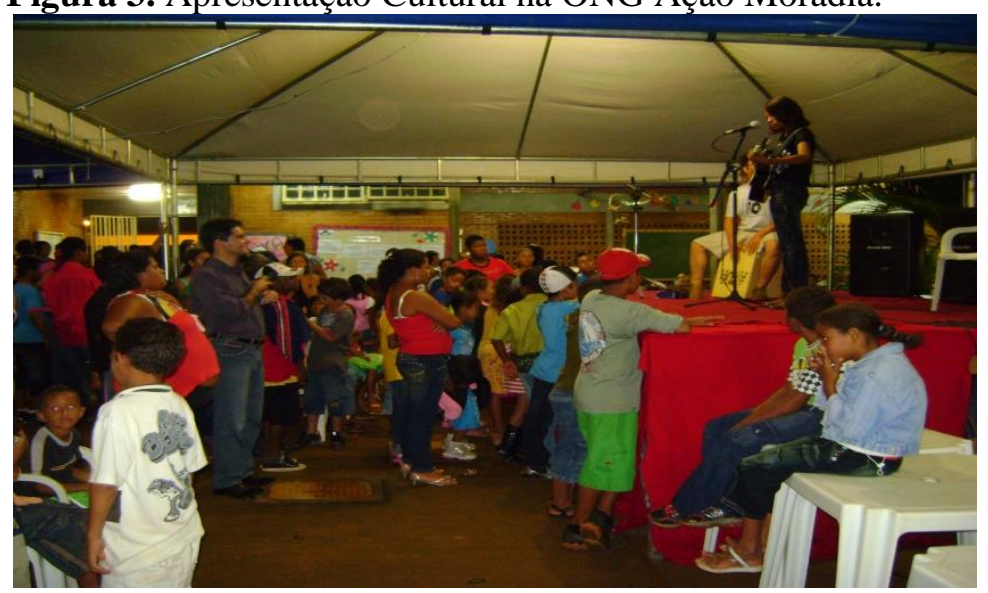

Fonte: Imagem cedida pela ONG Ação Moradia (Sem data).

Os moradores dos bairros do entorno da ONG tem plena consciência da existência de problemas relacionados com violência e drogas, assim como também, da falta de 
"opções" de lazer, escolas e outros equipamentos públicos, motivo pelo qual há uma demanda reprimida por parte da população por locais onde as crianças e adolescentes possam frequentar fora dos horários escolares, tornando-se a ONG Ação Moradia, um espaço significativo para preencher a falta de equipamentos públicos correlatos.

Em relação a parceria com outras entidades com fins parecidos, foi possível identificar apenas que a ONG participa de encontros mensais da denominada "Rede Leste", onde moradores, vereadores, agentes de saúde, entidades sociais como a própria ONG Ação Moradia e outras pessoas envolvidas com projetos sociais nos bairros do entorno, dialogam e debatem sobre as problemáticas existentes e assim pensar soluções.

Mas segundo um dos gestores da ONG, era possível perceber que em tais reuniões faltava a existência de um diálogo mais concreto, isto é, capaz de ocasionar mudanças, de fato, no bairro, uma vez que os próprios representantes da PMU tinham dificuldades, inclusive, para se "abrirem" a esse diálogo.

Para possibilitar todas as suas atividades a ONG sempre procurou buscar meios e parcerias tanto de natureza filantrópica quanto assistencialista. Tomando como exemplo o ano de 2015, o gestor D3 afirmou que a principal fonte de recursos financeiros da ONG era a Prefeitura Municipal de Uberlândia por meio da captação de recursos de subvenção social.

O dinheiro vem, mas ele não está vinculado a uma parceria técnica, ela
está vinculado até a outra visão, uma visão mais de prestação de
serviços pro governo. O que nós estamos fazendo na verdade é a função
que o governo deveria fazer. Ele não podendo fazer e o governo federal
cobrando ações que hoje são direitos dos cidadãos, que são direitos da
assistência social, já passa a ser uma obrigação do governo, como ela
não pode, e não têm condiçães de prover, ele recorre, para a iniciativa
privada e para as ONGs para atender aquilo que ele tem obrigação de
fazer e prestar contas. Então não é bem um apoio espontâneo, mas sim
um cumprimento de metas para com o governo federal (D3).

Vale destacar ainda, o fato de que o mesmo gestor demonstra clareza política quanto ao papel da associação num contexto de reconhecimento de que os poderes públicos não estão cumprindo efetivamente com a tarefa de criação de condições objetivas para atendimento de direitos da população como um todo.

Entretanto, esta "dependência" de recursos para com a PMU é considerada "desconfortável" para a ONG, devido ao fato de constituir-se uma relação econômica "vulnerável" derivada de certa "dependência" econômica instituída com praticamente um único "parceiro". Situação esta motivada, em grande parte pela conjuntura, ao parecer, provocada em certa medida pelas ações econômicas e sociais implementadas pelo governo federal nos últimos anos.

O parceiro principal que nós temos hoje é a prefeitura municipal de Uberlândia, o que nos deixa em uma situação muito vulnerável, pois quando você está muito dependente de um único parceiro, e esse parceiro não tem dinheiro, você também passa a ter dificuldade, que éo que está acontecendo hoje. (D3).

Por outro lado, além das verbas advindas do poder público, a ONG Ação Moradia conta com recursos próprios vindos das suas unidades produtivas e da festa junina que a mesma organiza anualmente. A instituição também procura "captar" recursos por meio da 
elaboração de projetos destinados ao atendimento de editais publicados, tanto por instituições privadas quanto pelo poder público. Entretanto, conseguir esse tipo de recurso é considerado complicado e burocrático, além de exigir competência técnica para a sua realização.

Diante do percurso realizado na pesquisa, foi possível elencar as influências e impactos da ONG em todo o seu período de atuação, levando em consideração o prazo temporal do mestrado.

\section{Considerações finais}

Com base na pesquisa realizada é possível afirmar inicialmente que para responder à pergunta problematizadora formulada torna-se necessário compreender dialeticamente que a ONG Ação Moradia encontra-se historicamente condicionada e até, de alguma forma, determinada pelas condições econômicas e sociais decorrentes do contexto internacional e nacional.

Vale ressaltar que os limites, possibilidades e perspectivas futuras da associação também foram e encontram-se, obviamente condicionados pelas características territoriais, econômicas, sociais e culturais dos bairros localizados no entorno da ONG. Especificamente, em se tratando do principal bairro desse entorno, o Morumbi, por isso a relevância de identificar e analisar geograficamente neste trabalho, parte da sua história, pautada por conflitos e interesses de mercado e com políticas de planejamento urbano fundamentadas ideologicamente em interesses econômicos imobiliários pouco ou nada relacionados com os interesses próprios da comunidade do bairro.

Foi possível constatar que grande parte dos programas e projetos instituídos ao longo da história pela ONG não foram unicamente relacionados ao combate à fome, mas também, foram sendo incorporadas ações decorrentes da necessidade por parte da comunidade de enfrentar os desafios da violência urbana, do consumo de drogas e do tempo disponível para crianças, adolescente e aposentados, diante da falta objetiva de equipamentos urbanos suficientes para atender demandas da população por educação, saúde, lazer, entre outros.

Ainda em relação aos limites, possibilidades e perspectivas de futuro da ONG Ação Moradia, vale ressaltar que a pesquisa de campo possibilitou identificar, dentre outros aspectos, que por diversos motivos a instituição tem apresentado dificuldades objetivas para monitorar e estabelecer processos avaliativos relacionados ás suas ações, bem como, aquelas relacionadas com o necessário gerenciamento dos dados e informações compiladas, resultando disto uma visão ainda difusa sobre os reais impactos produzidos ao longo de sua história.

Em relação aos impactos positivos, cabe destacar aqui, a importância e o reconhecimento de parte da comunidade em relação às moradias construídas com tecnologia própria (tijolo ecológico), bem como, os depoimentos dos usuários e exusuários entrevistados, para os quais a experiência vivida na ONG possibilitou não somente ganhos financeiros resultantes do trabalho ofertado, tanto nas unidades de produção quanto pelos empregos criados no interior da entidade, mas também, possibilidades de construção de identidades singulares, principalmente femininas, dotadas de independência econômica e afetiva em relação aos maridos e os filhos, bem como se encontram emocionalmente mais estáveis, em decorrência da convivência e das amizades constituídas entre pares dotadas de dificuldades e problemas cotidianos semelhantes. 
Por outro lado, coloca-se também como um dos pontos limitadores das ações da ONG Ação Moradia, críticas relacionadas com a natureza filosófica das suas ações e suas possíveis implicações para o desenvolvimento social da comunidade.

$\mathrm{O}$ primeiro aspecto identificado na presente pesquisa relaciona-se com o fato de que, independentemente das suas intenções, ao apoiar filantropicamente políticas públicas que não são instituídas para atender em plenitude os direitos sociais da comunidade, a ONG Ação Moradia pode estar contribuindo, contraditoriamente, para desobrigar o poder público do atendimento efetivo de necessidades e demandas sociais da comunidade, como ainda, para desmobilizar politicamente à população afetada, por falta, dentre outros, de uma estratégia de formação política mais crítica da comunidade em relação aos limites e possibilidades do desenvolvimento social no contexto do capital.

$\mathrm{O}$ segundo aspecto refere-se à natureza filosófico-pedagógica dos cursos ministrados na ONG, os quais por estarem em grande medida ancorados no pressuposto de oferecer à comunidade cursos profissionalizantes em busca da promoção de uma pretendida autossustentação, podem não estar contribuindo, entre outros, para elevar intelectualmente à consciência das camadas populares em busca da compreensão de sua própria concepção de classe oprimida e das estratégias que esta classe poderia realizar para acessar os seus direitos no âmbito das lutas populares, mas também e inclusive, para alcançar aquilo que foi apresentado pelos gestores entrevistados como perspectiva de futuro para a própria ONG.

Por todos esses motivos, para Marx a superação de todas as mazelas sociais somente poderá ser alcançada por meio de uma revolução social capaz de superar, dentre outros, a emancipação política alcançada no sistema capitalista, por outra relacionada com uma efetiva emancipação humana. "Revolução social, aqui, significa uma transformação que modifique, a partir da raiz- que é a sociedade civil-, a velha ordem social" (TONET, 2010, p. 30).

Assim,

\begin{abstract}
A emancipação política, expressa pela cidadania e pela democracia, é, sem dúvida, uma forma de liberdade superior á liberdade existente na sociedade feudal, mas, na medida em que deixa intactas as raízes da desigualdade social, não deixa de ser ainda uma liberdade essencialmente limitada, uma forma de escravidão (TONET, 2010, p. 27).
\end{abstract}

Em resumo, para além da formação técnica-profissional torna-se necessário que a ONG Ação Moradia promova uma reflexão político-pedagógica de suas ações formativas, tendo em vista a necessidade de incluir nelas a formação para a emancipação política e humana da comunidade, com base nas reflexões de Marx para que a comunidade possa num campo de efetiva liberdade e autonomia intelectual, buscar as suas próprias bases de sua sobrevivência, com dignidade e qualidade de vida.

\title{
Referências
}

AÇÃO MORADIA. Estatuto Social da ONG Ação Moradia. Uberlândia: 2004.7 p. Disponível em: <http://acaomoradia.org.br/wp/wp-content/uploads/2011/02/Estatuto.pdf> Acesso em: 03 mar. 2015. 
ARAÚJO SOBRINHO, F. L. Evolução Urbana e moradia popular em Uberlândia/ MG: Estudo de caso do Santa Mônica II. 1995. 131 f. Monografia Instituto de Geografia. Universidade Federal de Uberlândia. Uberlândia, 1995. Disponível em: <http://www.geografiaememoria.ig.ufu.br/downloads/011_Fernando_Luiz_Araujo_Sobrin ho.pdf> Acesso em: 12 mai 2015.

BRASIL. Censo Demográfico: 1980, 1991, 2004 e 2010, e Contagem da População 1996. Disponível: <http://seriesestatisticas.ibge.gov.br/series.aspx?vcodigo=POP122. > Acesso em: 05 mar. 2015.

CAMBA, S. V. ONGs e escolas públicas: uma relação em construção. São Paulo: Paulo Freire, 2009.

CARLOS, A. F.A. A cidade. São Paulo: Contexto, 2005.

COUTINHO, J. As ONGs: Origens e (des) caminhos. Disponível em: <www.pucsp.br/neils/downloads/v13_14_joana.pd>. Acesso em: 18 nov. 2015.

DAVIS, M. Planeta Favela. São Paulo: Boitempo, 2006.

FRANÇA FILHO, G. C. Terceiro Setor, Economia Social, Economia Solidária e Economia Popular: Traçando fronteiras conceituais. Revista Bahia Análise de Dados. Salvador. v. 12, n. 1, p. 9-19, junho 2002 .

MARTINS, J. A pesquisa qualitativa. In: Fazenda, Ivani (Org.). Metodologia da pesquisa educacional. São Paulo: Cortez, 1994, p. 49-58.

MEIRA, J.C. ONGs e Reforma do Estado no Brasil: Ressignificação da cidadania ou esvaziamento político dos movimentos sociais? 2009. 183 f. Dissertação de Mestrado (Mestrado em História). Universidade Federal de Uberlândia: Uberlândia, 2009.

PALAFOX, G.H. M. Breves Considerações a Respeito do Materialismo Históricodialético. Mimeo, 2013.

PEREIRA, T. D. O Não Governamental em Questão: estudo sobre o universo ABONG. Rio de Janeiro: FASE, 2003.

PRÓ BONO. Manual do Terceiro Setor. São Paulo. 2005. Disponível em: $<$ http://www.probono.org.br/arquivos/file/manualterceirosetor.pdf >. Acesso em: ago. 2015.

RAMIRES, J.C.L.; SANTOS, M.A.F. Percepção espacial da violência e do medo pelos moradores dos bairros Morumbi e Luizote de Freitas em Uberlândia/MG. Sociedade \& Natureza, Abr/2009. Uberlândia. p. 131-145. Disponível: < http://www.seer.ufu.br/index.php/sociedadenatureza/article/view/9463/5754> Acesso em: 05 jan. 2015. 
SANTOS, M. Metrópole Corporativa Fragmentada: O Caso de São Paulo. São Paulo: Nobel, 1990.

TONET, I. A propósito de "Glosas críticas". In: MARX, K. Glosas críticas marginais ao artigo "O rei da Prússia e a reforma social”. De um prussiano. Tradução Ivo Tonet. São Paulo: Expressão Popular, 2010, 80p.

\footnotetext{
${ }^{1}$ Mestre em Educação pela Universidade Federal de Uberlândia. Licenciada em Geografia pela Universidade Federal de Uberlândia (Universidade Federal de Uberlândia - milenaabadia@ hotmail.com).

${ }^{2}$ Doutor em Educação e Currículo (2001), ambos pela Pontifícia Universidade Católica de São Paulo. É Professor Titular da Universidade Federal de Uberlândia - UFU, lotado na Faculdade de Educação Física FAEFI e professor permanente, membro da linha de Políticas e Gestão da Educação do Programa de Pósgraduação em Educação da Faculdade de Educação da UFU (Universidade Federal de Uberlândia gabmpalafox@hotmail.com).
}

Recebido: Abril/2016.

Aprovado: Maio/2017. 